\title{
Fallbeispiel: Verkauf von Leasingforderungen
}

Zur Refinanzierung des Kfz-Leasinggeschäfts verkauft die NordLeasing $\mathrm{GmbH}$ im Jahresdurchschnitt $1 / 6$ ihrer gewerblichen Leasingforderungen in Höhe von 30 Mio. EUR an die $A B C$ Factoring-Bank $A G$ in Hamburg. Der Jahresumsatz (gewerbliche Leasingverträge) der NordLeasing GmbH beträgt 180 Mio. EUR.

Die ABC-Factoring-Bank bietet der NordLeasing $\mathrm{GmbH}$ die nachstehenden Konditionen zur Refinanzierung an:

Konditionen für den Forderungsverkauf:

\begin{tabular}{|l|l|l|l|l|}
\hline $\begin{array}{c}\text { Factoringge- } \\
\text { bühr }\end{array}$ & \multicolumn{1}{|c|}{ Sollzinsen } & Habenzinsen & $\begin{array}{l}\text { Auszahlung bei } \\
\text { Ankauf }\end{array}$ & Bardepot \\
\hline $\begin{array}{l}1,5 \% \text { auf den } \\
\text { Jahresumsatz }\end{array}$ & $\begin{array}{l}12 \% \text { p. a. auf die } \\
\text { Summe der an- } \\
\text { gekauften Lea- } \\
\text { singraten }\end{array}$ & $\begin{array}{l}6 \% \text { p. a. auf das } \\
\text { Bardepot }\end{array}$ & $\begin{array}{l}90 \% \text { des Forde- } \\
\text { rungsbetrages }\end{array}$ & $\begin{array}{l}10 \% \text { des For- } \\
\text { derungsbetra- } \\
\text { ges }\end{array}$ \\
\hline \multicolumn{3}{|l|}{ Bonitätsprüfungsgebühr einmalig $0,15 \%$ auf die angekauften Leasingraten } \\
\hline
\end{tabular}

\section{Aufgaben}

a) Ermitteln Sie den Liquiditätsgewinn für die NordLeasing GmbH durch den Forderungsverkauf!

b) Unter welchen Voraussetzungen ist die $A B C$-Factoring $\mathrm{GmbH}$ bereit, die gewerblichen Leasingraten der NordLeasing GmbH anzukaufen?

c) Beschreiben Sie die Funktionen, die die $A B C$-Factoring $G m b H$ in diesem Fall für die NordLeasing GmbH übernimmt.

d) Welcher Vorteil ergibt sich für die NordLeasing $\mathrm{GmbH}$ aus der Refinanzierung und welche Nachteile ergeben sich aus diesem Leasingratenankauf für die $A B C$-Factoring $\mathrm{GmbH}$ ?

e) Errechnen Sie die Factoringkosten, die die ABC-Factoring-Bank der NordLeasing GmbH in Rechnung stellt. 